\title{
The Effect of Video Imagery Training on Soccer Skills Performance of High School Players
}

\author{
Sara Majlesi' ${ }^{1}$, Dr. Lim Boon Hooi ${ }^{2}$, Dr. Pooya Nekooei ${ }^{3}$, Kamran Hosseinzadeh Ghasemabad ${ }^{4}$, Dr. \\ Behzad Alemi ${ }^{5}$, Paria Nekouei ${ }^{6}$ \\ ${ }^{1}$ Centre for Sport and Exercise Sciences, University of Malaysia, 50603 Kuala Lumpur, Malaysia \\ ${ }^{2}$ Centre for Sport and Exercise Sciences, University of Malaysia, 50603 Kuala Lumpur, Malaysia \\ ${ }^{3}$ Department of Physical Education and Sport Sciences, faculty of educational studies, UPM University, Serdang,Selangor, \\ Malaysia \\ ${ }^{4}$ Department of Physical Education and Sport Sciences, faculty of educational studies, UPM University, Serdang, Selangor, \\ Malaysia \\ ${ }^{5}$ Department of Physical Education and Sport Sciences, faculty of educational studies, UPM University, Serdang, Selangor, \\ Malaysia \\ ${ }^{6}$ University of Paderborn, Department of Sport and Health
}

\begin{abstract}
This study evaluated the effect of PETTLEP video imagery onreactive motor skill test (Total RMST time, sprint time, reactive agility time, passing time, and passing accuracy) among 32 Malaysian high school soccer players (mean age of 15.31 \pm 1.83 ) who were randomly assigned into an experimental group $(\mathrm{N}: 16)$ and a control group $(\mathrm{N}: 16)$. A pre-test-post-test design was used to evaluate the effect of the intervention on the high schoolplayers' soccer skill performance. The experimental group received 10minute PETTLEP video imagery trainingbefore their regular soccer training for eight weeks in addition to their regular soccer training, while thecontrol group only attended their regular soccer training. The data analysis revealed a significant effect of video imagery training on players' performance in the experimental group. The results showed that total RMST time, reactive agility time, passing time, and passing accuracy were statistically different within the experimental group $\mathrm{F}(15,154.993)=14.440, \mathrm{p}=<$ .001 , Wilks' $\Lambda=.050$ and between groups $F(5,56.00)=379.774, p=<.001$, Wilks' $\Lambda=.050$ after receiving the training, except for the sprint time which was not significant. The findings of this study provide evidence that eight weeks ofPETTLEPvideo imagery training interventioncan significantly improve soccer players' total RMST time, reactive agility time, passing time, and passing accuracy. These findings could be integrated into training programs by coaches and players in order to improve the performance of different soccer skills among high school players.
\end{abstract}

Key Words: PETTLEP Video Imagery, Soccer Skills, Reactive Motor Skills Test (RMST)

\section{INTRODUCTION}

The importance of imagery in enhancing sports performance, decision making, and reactive agility time has attracted researchers' attention recently $[1,2]$. Imagery in sport refers to rehearsing physical skills cognitively without body movement [3] that can have a positive effect on both skill learning and competition preparation. Visualization and cognitive rehearsal are often used by sport psychologists to help individuals enhance their motivation and self-confidence and reduce their competition anxiety. Training the mind has been shown to be essential in successful sport performance, regardless of its application. Imagery can be beneficial inlearning skills, especially if it is combined with physical practice. The cognitive practice of physical skills in the absence of overt physical movement involves imaging a skill or part of a skill [4]. Also, it is the most common type of mental practice used in athletics [5, 6].It includes several internal processes to enhancemovement efficiencies includingautomaticity,precision, speed, and adaptability. It is believed that motor and sensory information is organized and integrated in these processes which are considered as complex central nervous system phenomena[7].

Based on previous research, imagery has been used for athletes in four functionally different categories including performance enhancement, affective and cognitive modification, rehabilitation and arousal regulation. Imagery has been used successfully within these categories in various sports and has been shown to be effective onself-confidence, skill acquisition, anxiety management, and pain control[8-10]. It has also been reported that athletes have used imagery for learning and rehearsal of tactics, strategies, and 
game plans [11]. It has been suggested that imagery can be helpful in rehearsing tactical skills and strategies and solving problems arising unexpectedly in competitions [12]. The number of studies on the use of imagery in developing cognitive plans for athletes in competitions has been limited thus far. Developing and learning game plans and strategies using imagery first and subsequently practicing them mentally seems to be beneficial for athletes[12]. Positive images of what need to be performed and likely alternatives need to be incorporated by imagery to improve decision making during performance planning[13].

In team sports, especially soccer, players may improve their awareness of other members' respective roles and determine how to position themselves with regard to time and spaceamong other players[14]. In addition, coaches and players may develop game strategies and plans to use in the face of particular opponents prior to competitions[13]. Thus, they can integrate imagery into the players' pre-performance routine to refine particular strategies before participating in a competition[15]. Imagery can be used by athletes to tackle technical, tactical or timing problems arising during a competition or against a particular opponent.

There are two perspectives regarding the use of imagery: external imagery and internal imagery. In the external perspective which is predominantly visual, an athlete views himself as if they were in a film. Unlike the external imagery that uses a third-person perspective, the internal imagery is characterized by using a first-person perspective. Based on the available evidence, internal imagery is more effective than external imagery regarding sport performance improvement [16, 17].Internal imagery may have a more effective transfer to the learning of the skill. Holmes and Collins [18] suggested an internal imagery model that comprises physical, environment, task, timing, learning, emotion, and perspective factors (PETTLEP), on the basis of theory and research incognitive psychology,sport psychology, and neuroscience, with the goal of providing practical guidelines for the use of imagery by practitioners. In neuroscience, action observation is when athletes watch someone perform an action or specific task that lies within their motor repertoire and their brain stimulates the performance of that action. Imagery process and action observation have similar neural representations [19]. Such resonance supports the assumption that these common regions are essential in action anticipation, action recognition and goal recognition by the stimulation of the observed or imagined action. There is evidence to support the effectiveness of action observation through video imagery as a technique for improving sports performance [20, 21]. According to PETTLEP model, we can optimize imagery done through action observation videos with real practicerelated features such as adopting relevant positions to do the action observation orholding task-specific sport equipment[18].

Past researches show thatemploying imagery has a positive impact on sports performance[2228].Furthermore, other studies have demonstrated that PETTLEP video imagery training positively affected athletes' performance in different sports[29-33]. However, the findings of previous studies have been mixed, and concerns about research methods used in those studies have limited the dependability of their positive findings and gaining a clear understanding, emphasizing the need for future studies in imagery area. The use of PETTLEP video imagery has not been sufficiently investigated as a practical method in soccer players in order to balance their autonomic response with effect on their skill performance and reactive agility time. One possible reason is that there should be an expert to run the training protocol, which makes it more complicated to use by athletes themselves.Thus, the present study aims to determine whether the use of PETTLEP video imagery training improves high school soccer players' skill performance in terms of total reactive motor skill test time, reactive agility time, sprint time, passing time, and passing accuracy.

\section{METHOD}

\section{Participants}

The participants of the study were 32 high school male Malaysian soccer players (age mean of $15.31 \pm 1.83$ years old) who were selected from a well-known international school and played in the school soccer team at the time of the study. They possessed good soccer skills as the high school players with minimum 2 years' experience in 
playing soccer. The participants did not have any health and psychological issues. They participated in the school's soccer training three sessions a week for approximately 2 hours per session. All participants and their guardians were notified about the test procedure, and letters of consent were provided for all participants before conducting the study. Upon the beginning of the test, the researcher explained the research procedure to the participants, and they were assigned randomly into two groups, with 16 participants in each group using the Fishbowl technique.

\section{Equipment and Measurements}

In this study, a soccer field and futsal court were used for practice and experimental measurements. The equipment and material used in this study included the sport imagery ability questionnaire (SIAQ) developed and validated byWilliams and Cumming [34], timing gates (Brower Timing System Speed Trap Ii) validated by Shalfawi, et al. [35], soccer balls (Adidas Brazuca size 5), headphones (Original Beats EP on-ear headphone), NEC projectors and an Apple iPad. The equipmentwas internationally standard and were calibrated prior to the intended testing according to the manufacturers' standardized procedures.

\section{Data Collection}

The present study aimed to investigate the effects of video imagery training on soccer players' performance. After gaining permission from the high school authorities to conduct the study using their facilities, and prior to the pre-test, the researcher explained to the participants the importance of this research, different training objectives, training length and procedure, and the reactive motor skills test (RMST). The RMST test is a valid test that evaluates 4 different skills (passing time, passing accuracy, sprint time and reactive agility) as well as the total time of doing RMST.[36].

Before training, all participants gathered in the futsal hall, and the SIAQ was distributed among them to test their imagery ability with the aim of ensuring that enhancing performance would not depend upon individual imagery abilities. On the first day, all participants were tested after doing specific soccer warm-up compiled by the researcher. Reactive motor skills test (RMST) was performed three times to measure the participants' passing time, passing accuracy, speed, and reactive agility time, separated by at least three minutes of passive recovery. They were asked to do the test quickly and accurately. The time spent on each section was used to evaluate theperformance outcome (sprint, reactive agility time and passing) and the Total reactive motor skill test time. The best timing was recorded for each participant for analysis. After the pre-test, the experimental training was implemented before players' usual soccer practice for eight weeks in the experiment group twice a week based on the research literature of effective duration for PETTLEP video imagery training. Each training session was 10 minutes.

All players had their usual soccer practice after school. For the training sessions, the players wore their soccer team shirts, shorts, proper soccer cleats, and used the same soccer field where they had their routine training to have all the components of PETTLEP imagery in their training. The researcher used a video clip consisting of sprint, reactive agility time skills, and successful soccer passing with the correct techniques. After participants watching each skill, a written note on the screen appeared and asked them to close their eyes and imagine the movements while they were standing on the soccer field and had the soccer ball. Then after the given time for imagery in the video, a countdown to 3 with audio played on the screen for them to be ready for watching the next skill. Players had the exact same amount of time for watching and imaging each skill in the video before the countdown started to watch the next video based on PETTLEP model components [18]. After that, they performed soccer short passes, sprint and reactive agility time to complete their PETTLEP video imagery session. The rest of the PETTLEP video imagery training sessions followed the same procedure. Participants who had been assigned to the control group had their usual soccer training organized and supervised by their school soccer coach. In the post-test phase of the study, the researcher implemented the exact procedure of the pre-test evaluation with the participants who had participated in all training sessions. 


\section{RESULTS}

Prior to the inferential analysis of the data, the descriptive statistics including normality test, homogeneity of variance test, equality of groups at pre-test, were computed using exploratory data

Table 1. analysis. This analysis aimed to test the normal distribution of the variables and homogeneity of variance between groups prior to conducting inferential analyses. The descriptive statistic for all dependent variable isshowed in

Table 1:Descriptive Statistics for Dependent Variables

\begin{tabular}{lcccc}
\hline & \multicolumn{2}{c}{ Group I } & \multicolumn{2}{c}{ Group C } \\
\cline { 2 - 5 } & Mean & SD & Mean & SD \\
\hline Total RMST Time Pre test & 7.74 & 0.12 & 7.75 & 0.17 \\
Total RMST Time Post test & 7.26 & 0.13 & 7.67 & 0.18 \\
Sprint Time Pre test & 1.36 & 0.04 & 1.37 & 0.04 \\
Sprint Time Post test & 1.32 & 0.05 & 1.35 & 0.06 \\
Reactive agility time Pre test & 1.94 & 0.06 & 1.94 & 0.08 \\
Reactive agility time Post test & 1.8 & 0.08 & 1.93 & 0.09 \\
Passing Time Pre test & 4.44 & 0.02 & 4.44 & 0.04 \\
Passing Time Post test & 4.14 & 0.02 & 4.4 & 0.05 \\
Passing Accuracy Pre test & 4.25 & 1.15 & 4.16 & 1.21 \\
Passing Accuracy Post test & 5.56 & 1.26 & 4.25 & 1.39 \\
\hline
\end{tabular}

A normality test was run to evaluate the normal distribution of players in groups according to RMST test and imagery ability levels. To this end, Table 2, the values of kurtosis and skewness were between -2 and +2 that showed violation has not been occurred andplayers werenormally

Table 2:Kurtosis/Skewness Analysis for RMST and Imagery Ability in pretest

\begin{tabular}{llcccc}
\hline & & \multicolumn{2}{c}{ Group I } & \multicolumn{2}{c}{ Group C } \\
\hline \multirow{2}{*}{ Total RMST Time } & & P.Value & Std.Error & P.Value & Std.Error \\
\cline { 2 - 5 } Sprint Time & Skewness & -0.124 & 0.564 & -0.017 & 0.564 \\
& Kurtosis & -1.074 & 1.091 & -0.905 & 1.091 \\
Reactive agility time & Skewness & 0.197 & 0.564 & -0.043 & 0.564 \\
& Kurtosis & -0.515 & 1.091 & -1.057 & 1.091 \\
Passing Time & Skewness & -0.224 & 0.564 & -0.109 & 0.564 \\
& Kurtosis & -1.03 & 1.091 & -0.849 & 1.091 \\
Passing Accuracy & Skewness & 0.053 & 0.564 & 0.454 & 0.564 \\
\multirow{2}{*}{ Imagery Ability } & Kurtosis & -1.138 & 1.091 & -0.127 & 1.091 \\
& Skewness & 0.482 & 0.564 & 0.165 & 0.564 \\
& Kurtosis & 0.659 & 1.091 & -0.684 & 1.091 \\
& Skewness & -0.032 & 0.564 & 0.843 & 0.564 \\
\hline
\end{tabular}

The Levene's test were interpreted for evaluating whether the variances of two groups were approximately equal or homogeneous. In this case, we expect or perhaps even want the

Table 3, the groups' variances are not significantly different, so equal variances are assumed, and in variances of the groups in Levene's test to be nonsignificant at significance value greater than .05 , which is the assumption of the factorial MANOVA test. As it is shown in

this case, the probability is even greater than 0.01 . The assumption of homogeneity of variance has been met for both groups at Pre-test. 
Table 3:Test of Homogeneity of Variances

\begin{tabular}{lcc}
\hline & Test of Homogeneity of Variances & \\
\hline & Levene's Statistic & P.Value \\
\hline Total RMST Time & 1.505 & 0.222 \\
Sprint Time & 2.308 & 0.086 \\
Reactive agility time & 1.752 & 0.155 \\
Passing Time & 2.318 & 0.085 \\
Passing Accuracy & 0.174 & 0.913 \\
\hline
\end{tabular}

All of the players were tested for their imagery ability through the SIAQ questionnaire. The results of the SIAQ questionnaire only reported

Table 4, both groups were homogeneous and there were no differences in the participants' imagery ability between groups at pretest.

Table 4: Imagery Ability Homogeneity whether the players had an ability to do imagery, and the test did not rate them from the weakest to the strongest. As presented in

\begin{tabular}{lcccc}
\hline & Mean & SD & F & P.value \\
\hline Group I & 5.04 & 0.31 & 2.278 & 0.089 \\
Group C & 5.1 & 0.46 & & \\
\hline
\end{tabular}

\section{Inferential Analyses}

The research question of this study was Is there any significant difference in players' reactive Table 5,the results of the multivariate test show that there were statistically significant differences between and within groups and also there was a statistically significant interaction effect between Table 5:Multivariate Test motor skills test (RMST) within and between groups?. As it presented in

tests and groups of intervention on the combined dependent variables, $\mathrm{F}(15,154.993)=20.280, \mathrm{p}=$ $<.001$, Wilks' $\Lambda=.050$.

\begin{tabular}{lccccccc}
\hline \multicolumn{7}{c}{ Multivariate Tests } \\
\hline Effect Between & Intercept & Wilks' Lambda & $<0.001$ & 52115.720 & 5 & 56.000 & $<0.001$ \\
Groups & Group & Wilks' Lambda & 0.089 & 14.440 & 15 & 154.993 & $<0.001$ \\
Within Groups & Tests & Wilks' Lambda & 0.029 & 379.774 & 5 & 56.000 & $<0.001$ \\
& Tests * Group & Wilks' Lambda & 0.050 & 20.280 & 15 & 154.993 & $<0.001$ \\
\hline
\end{tabular}

Furthermore, the results of pairwise comparison within groups as presented in Table 6, showed there were statistically significant differences within group in all RMST tests variables.According

Table 6, the players' reactive motor skills test (RMST) value was, Total RMST time MD= $0.478, \mathrm{P}<0.001$, Sprint Time $\mathrm{MD}=.0 .43$, $\mathrm{p}<0.001$, Reactive agility time skill $\mathrm{MD}=.134$, $\mathrm{p}<0.001$, passing time $\mathrm{MD}=.303, \mathrm{p}<0.001$, Passing Accuracy $\mathrm{MD}=-1.313, \mathrm{p}<0.001$ inthe imagery groupthat shows there was a statistically Table 6:Pairwise Comparison Within Groups significant difference between pre-test and posttest in the experimental group; however, there was no significant difference in the control group. The mean of each group at pre- and post-test shows that the players' reactive motor skills test (RMST) improved after eight weeks of training in the video imagery group. 


\begin{tabular}{|c|c|c|c|c|c|c|c|c|c|c|}
\hline & \multirow[t]{2}{*}{ Measure } & & & \multirow[t]{2}{*}{ MD } & \multirow{2}{*}{$\begin{array}{l}\text { Std. } \\
\text { Error }\end{array}$} & \multirow[t]{2}{*}{ Sig. ${ }^{b}$} & \multicolumn{2}{|c|}{$\begin{array}{l}\text { 95\% Confidence } \\
\text { Interval for } \\
\text { Difference }^{\mathrm{b}} \\
\end{array}$} & \multirow{2}{*}{$\begin{array}{l}\text { Mean } \\
\text { Pre }\end{array}$} & \multirow{2}{*}{$\begin{array}{c}\text { Mean } \\
\text { Post }\end{array}$} \\
\hline & & & & & & & $\begin{array}{l}\text { Lower } \\
\text { Bound }\end{array}$ & $\begin{array}{l}\text { Upper } \\
\text { Bound }\end{array}$ & & \\
\hline \multirow{2}{*}{$\begin{array}{l}\text { Total RMST } \\
\text { time }\end{array}$} & Group I & Pre & Post & $.478^{*}$ & 0.048 & $<0.001$ & 0.383 & 0.573 & 7.738 & 7.26 \\
\hline & Group C & Pre & Post & 0.074 & 0.048 & 0.123 & -0.021 & 0.17 & 7.749 & 7.674 \\
\hline \multirow{2}{*}{ Sprint Time } & Group I & Pre & Post & $.043^{*}$ & 0.01 & $<0.001$ & 0.023 & 0.062 & 1.364 & 1.321 \\
\hline & Group C & Pre & Post & 0.013 & 0.01 & 0.185 & -0.006 & 0.033 & 1.366 & 1.353 \\
\hline \multirow{2}{*}{$\begin{array}{l}\text { Reactive agility } \\
\text { time }\end{array}$} & Group I & Pre & Post & $.134^{*}$ & 0.012 & $<0.001$ & 0.11 & 0.158 & 1.936 & 1.803 \\
\hline & Group C & Pre & Post & 0.014 & 0.012 & 0.253 & -0.01 & 0.038 & 1.939 & 1.926 \\
\hline \multirow{2}{*}{ Passing Time } & Group I & Pre & Post & $.303^{*}$ & 0.044 & $<0.001$ & 0.215 & 0.391 & 4.439 & 4.136 \\
\hline & Group C & Pre & Post & 0.047 & 0.044 & 0.289 & -0.041 & 0.135 & 4.444 & 4.398 \\
\hline Passing & Group I & Pre & Post & $-1.313^{*}$ & 0.223 & $<0.001$ & -1.758 & -0.867 & 4.25 & 5.563 \\
\hline Accuracy & Group C & Pre & Post & -0.094 & 0.223 & 0.675 & -0.539 & 0.352 & 4.156 & 4.25 \\
\hline
\end{tabular}

The results of between group pairwise comparison in Table 7 showed that there is a statistically significant difference between groups in players' reactive motor skills (RMST) after eight weeks of experimental training. As Table 7shows, the players' RMST value forPETTLEPimagerygroup (I)vs. control group $(\mathrm{C})$ was, Total reactive motor skill test timeMD $=-414, \mathrm{p}<.0001$, Sprint time $\mathrm{MD}=-.031, \mathrm{p}<.725$, Reactive agility time skill $\mathrm{MD}=-.123, \mathrm{p}<.0001$, Passing Time $\mathrm{MD}=-.262, \mathrm{p}$ $<.001$ and passing Accuracy $\mathrm{MD}=1.188, \mathrm{p}<$

.044.Thus, the results showed there was a statistically significant difference between the groups in all RMST variable except sprint time that did not showed any significant difference between groups after 8-weekPETTLEP imagery training.The results show that eight weeks of PETTLEP video imagery intervention had a significant effect on players' reactive motor skills variables, however, did not have any significant impact on the players' sprint performance.

Table 7:Pairwise Comparison Between Groups

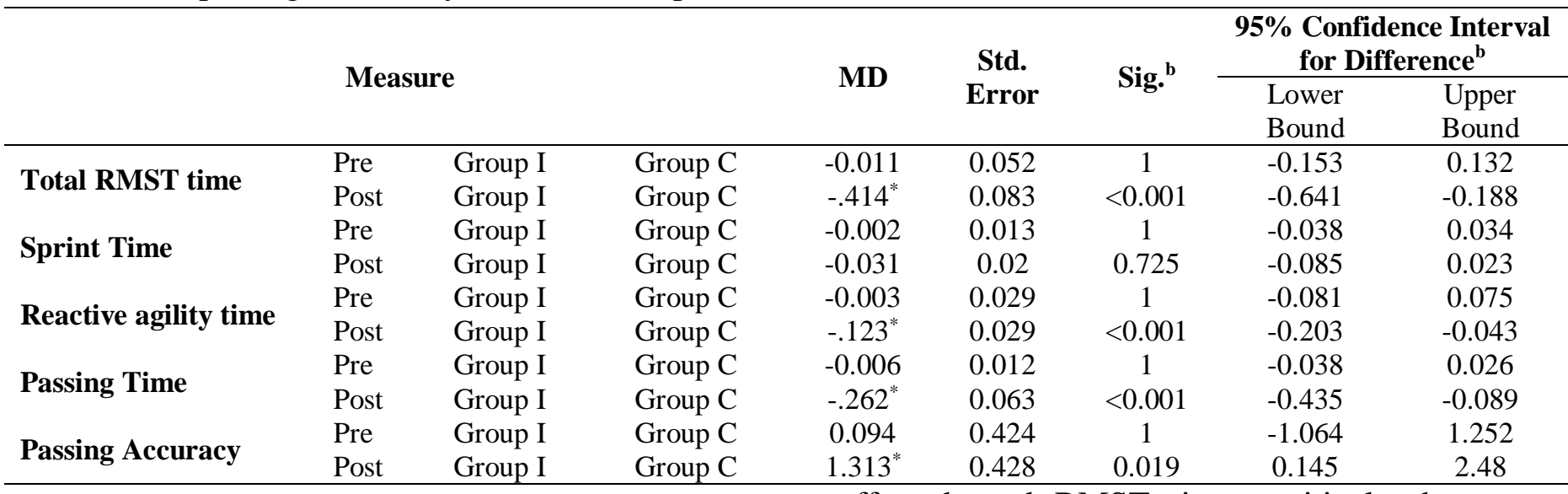

\section{DISCUSSION}

The current study evaluated the effects of an eight-week PETTLEP video imagery intervention, on high school soccer players' skill performance. The participants took RMSTthat covering sprint time, reactive agility time, passing time, and passing accuracy before and after the video imagery training. The research results showed that total RMST time significantly improved $\mathrm{F}(3,60)$ $=706.245, \mathrm{p}=0.001$ within group after eight weeks of PETTLEP video imagery $\mathrm{MD}=0.478, \mathrm{P}$ $<0.001$. Therefore, reactive agility time, passing time and passing accuracy improved in the experimental group and these improvements affected total RMST time positively, however, there was no significant improvement in the sprint time in the PETTLEP video imagery group. Although there was not any significant improvement in sprint time in the experimental group, it did not affect the overall improvement in total RMST time as the other test components significantly improved it.

Previous research findings showed that PETTLEP video imagery improved reactive agility time, passing time and passing accuracy $[32,37]$ which are supported by the findings of the current study. Therefore, soccer players and coaches can include PETTLEP video imagery in their exercise routine 
to improve the performance of selected skills. It is possible that the duration of PETTLEP video imagery training was not enough to affect the players' sprint time or PETTLEP video imagery training with an internal perspective, did not affect the players' sprint time as much as the other training types.

However, various researchers, coaches and athletes use imagery since it is recognized as an effective tool for the successful performance of elite athletes through affecting their psychological state positively [38-41]. Studies have proven that the majority of elite athletes deliberately use imagery. Similarly, most sports psychologists apply imagery systematically to increase the athletes' performance [42, 43]. HammoudiNassib, et al. [44] found that the imagery training improves the sprint performance that is support the finding of this study. Pain, et al. [45] theorized that imagery training not only improves the performance of athletes having specific training but the performance of athletes having nonspecific training as well. Munroe-Chandler, et al. [46] suggested that imagery training evolves from early childhood to early adolescence among children. Although this study found no significant improvements as a result of PETTLEP video imagery training in sprint time, more research is necessary to explore the effect of PETTLEP video imagery on players' sprint time in longer durations and using different perspectives.

This study also examined the impact of PETTLEP video imagery on reactive agility time and the possibility of improving reaction to unpredictable stimuli using these interventions. The results showed significant improvements in players' reactive agility time, $\mathrm{F}=1053.497, \mathrm{p}=<0.001$ as a result of PETTLEP video imagery within the experimental group. Based on the research findings, video imagery training, PETTLEP significantly improved reactive agility time after eight weeks of training, $\mathrm{MD}=.134, \mathrm{p}<0.001$. Thus, it could be recommended that soccer players use PETTLEP video imagery along with their usual soccer training to enhance their reactive agility time. The findings of this study related to reactive agility time are in line with the previous research that showed imagery training could improve decision time, which leads to better reaction [47].
The findings of this study showed that PETTLEP video imagery, HRVB and concurrent training improved the players' passing accuracy, $\mathrm{F}=$ $142.318, \mathrm{p}=<0.001$ and passing time, $\mathrm{F}=$ 274.702, $\mathrm{p}=<0.001$ within the groups. The finding is in accord with the findings of past studies that revealed significant improvements in athletes' passing performance and accuracy after receiving PETTLEP video imagery training. Battaglia, et al. [48] demonstrated that using video for imagery training was highly advantageous as imagery is more beneficial when it is vivid and detailed. Besides, they suggested that it could be a suitable type of imagery training for all levels of imagery ability because players can see the successful desired performance very clearly and be mentally prepared for an actual event or competition.

In this study, the researcher used PETTLEP video imagery to help soccer players create a clear image with more detail and vividness. The previous findings by Mazli, et al. [32], who examined the effects of traditional imagery and PETTLEP model on netball players, showed that the participants in the PETTLEP video and audio imagery groups had better passing accuracy compared to the traditional imagery group. These findings are supported by the findings of the current study that showed PETTLEP video imagery could improve the passing accuracyof soccer players. One reason for these improvements can be the increase in the attention and focus as a result of PETTLEP video imagery training, which leads to accuracy improvement among athletes.

The findings of the present study related to the effectiveness of PETTLEP video imagery training on sports performance are also in line with the previous studies that showed PETTLEP video imagery training can improve players' passing accuracy and passing time $[22,26,30,49]$. The PETTLEP video imagery has been used in other sports to improve athletic performance as well. Cumming, et al. [50] investigated the effect of video imagery training on female basketball players and concluded that PETTLEP video imagery training improved basketball players' shooting accuracy that supports the finding of this study about the impact of PETTLEP video imagery on male soccer players' passing accuracy. 
While research literate on PETTLEP video imagery training is vast in other sports, this study focused on the use of video imagery training among high school soccer players.

\section{CONCLUSION}

The findings of this study show that eight weeks of PETTLEP video imagery had a significant within- and between- group effect on the soccer players' RMST, passing time, passing accuracy and reactive agility time, with the exception of sprint time which was not improved significantly between the groups as a result of imagery training in the study.The findings of the current study revealed that players' performance was significantly improved from pretest to posttest, so the PETTLEP video imagery intervention was helpful for athletes. Thus, it was concluded that PETTLEP video imagery helped soccer players to improve the selected soccer skills and it can be vital in helping athletes enhance their performance at all levels of competition. It can also be useful in future studies in sports psychology.

This study was conducted for 8 weeks among high school soccer players who played soccer at the REFERENCES

[1] Z. Yijing, D. Xiaoping, L. Fang, J. Xiaolu, and W. Bin, "The effects of guided imagery on heart rate variability in simulated spaceflight emergency tasks performers," BioMed research international, vol. 2015, 2015.

[2] X. Jing, P. Wu, F. Liu, B. Wu, and D. Miao, "Guided imagery, anxiety, heart rate, and heart rate variability during centrifuge training," Aviation, space, and environmental medicine, vol. 82, no. 2, pp. 92-96, 2011.

[3] T. Morris and A. P. Watt, Imagery in sport. Human Kinetics, 2005.

[4] P. J. Cohn, "Preperformance Routines in Sport: Theoretical Support and Practical Applications," Sport Psychologist, vol. 4, no. 3, 1990.

[5] D. Gould, R. Weinberg, and A. Jackson, "Mental Preparation Strategies, Cognitions, and Strength Performance," international school level. Based on the findings of the study, we make some recommendations for future possible studies. This study showed that PETTLEP video imagery improves the players' sprint time within group, but the improvement was not significant while comparing with other groups. It is possible that the duration of PETTLEP video imagery training was not enough to affect the players' sprint time or PETTLEP video imagery training with an internal perspective, did not affect the players' sprint time as much as the other training. Therefore, more research is required to explore the effect of PETTLEP video imagery on players' sprint time in longer durations and using different perspectives. Furthermore, longitudinal studies of physiological and psychological aspects of athletes' performance will inform future interventions about the most efficacious constructs on which to focus for each level of performance. It is also important to carry out interventional studies with higher number of elite players to extend the findings of longitudinal studies and provide an in-depth understanding of the psychological effects of training on athletes' performances

Journal of Sport Psychology, vol. 2, no. 4, 1980.

[6] J. P. Whelan, M. J. Mahoney, and A. W. Meyers, "Performance enhancement in sport: A cognitive behavioral domain," Behavior Therapy, vol. 22, no. 3, pp. 307327, 1991.

[7] D. Gould, D. K. Voelker, N. Damarjian, and C. Greenleaf, "Imagery training for peak performance," 2014.

[8] M. Brouziyne and C. Molinaro, "Mental imagery combined with physical practice of approach shots for golf beginners," (in English), Perceptual and Motor Skills, Article vol. 101, no. 1, pp. 203-211, Aug 2005.

[9] R. W. Coelho, W. Campos, S. G. Da Silva, F. H. A. Okazaki, and B. Keller, "Imagery intervention in open and closed tennis motor skill performance," (in English), 
Perceptual and Motor Skills, Article vol. 105, no. 2, pp. 458-468, Oct 2007.

[10] S. Gordon, R. Weinberg, and A. Jackson, "Effect of internal and external imagery on cricket performance," Journal of Sport Behavior, 1994.

[11] S. E. Short, A. Tenute, and D. L. Feltz, "Imagery use in sport: Mediational effects for efficacy," Journal of Sports Sciences, vol. 23, no. 9, pp. 951-960, 2005.

[12] F. Malouin and C. L. Richards, "Mental practice for relearning locomotor skills," Phys Ther, vol. 90, no. 2, pp. 240-51, Feb 2010.

[13] K. J. Munroe-Chandler, C. R. Hall, G. Fishburne, J. O, and N. Hall, "The content of imagery use in youth sport," International Journal of Sport and Exercise Psychology, vol. 5, no. 2, pp. 158-174, 2007.

[14] A. Guillot, E. Nadrowska, and C. Collet, "Using motor imagery to learn tactical movements in basketball," Journal of Sport Behavior, vol. 32, no. 2, pp. 189206, 2009.

[15] A. Guillot and C. Collet, "Construction of the motor imagery integrative model in sport: a review and theoretical investigation of motor imagery use," International Review of Sport and Exercise Psychology, vol. 1, no. 1, pp. 31-44, 2008.

[16] Callow, R. Roberts, L. Hardy, D. Jiang, and M. G. Edwards, "Performance improvements from imagery: evidence that internal visual imagery is superior to external visual imagery for slalom performance," Front Hum Neurosci, vol. 7, p. 697, 2013.

[17] C. J. Olsson, B. Jonsson, and L. Nyberg, "Internal imagery training in active high jumpers," Scand J Psychol, vol. 49, no. 2, pp. 133-40, Apr 2008.
[18] P. S. Holmes and D. J. Collins, "The PETTLEP Approach to Motor Imagery: A Functional Equivalence Model for Sport Psychologists," (in English), Journal of Applied Sport Psychology, Article; Proceedings Paper vol. 13, no. 1, pp. 6083, Mar 2001.

[19] M. Conson, M. Sarà, F. Pistoia, and L. Trojano, "Action observation improves motor imagery: specific interactions between simulative processes," Experimental brain research, vol. 199, no. 1, pp. 71-81, 2009.

[20] N. Ram, S. M. Riggs, S. Skaling, D. M. Landers, and P. McCullagh, "A comparison of modelling and imagery in the acquisition and retention of motor skills," J Sports Sci, vol. 25, no. 5, pp. 587-97, Mar 2007.

[21] J. Cumming and R. Ramsey, "Imagery interventions in sport," in Advances in applied sport psychology: Routledge, 2008, pp. 15-46.

[22] K. J. Munroe-Chandler, C. R. Hall, G. J. Fishburne, L. Murphy, and N. D. Hall, "Effects of a cognitive specific imagery intervention on the soccer skill performance of young athletes: Age group comparisons," Psychology of Sport and Exercise, vol. 13, no. 3, pp. 324-331, 2012.

[23] E. Kizildag and M. Ş. Tiryaki, "IMAGERY USE OF ATHLETES IN INDIVIDUAL AND TEAM SPORTS THAT REQUIRE OPEN AND CLOSED SKILL 1, 2," Perceptual \& Motor Skills, vol. 114, no. 3, pp. 748-756, 2012.

[24] S. Koehn, T. Morris, and A. P. Watt, "Imagery intervention to increase flow state and performance in competition," Sport Psychologist, vol. 28, no. 1, pp. 4859, 2014.

[25] N. Robin, L. Dominique, L. Toussaint, and Y. Blandin, "Effects of motor imagery training on service return accuracy in tennis: The role of imagery ability," 
International Journal of Sport and Exercise Psychology, vol. 5, no. 2, pp. 175-186, 2007.

[26] T. Seif-Barghi, R. Kordi, A.-H. Memari, M.-A. Mansournia, and M. Jalali-Ghomi, "The effect of an ecological imagery program on soccer performance of elite players," Asian journal of sports medicine, vol. 3, no. 2, p. 81, 2012.

[27] Z. Wang et al., "The effect of motor imagery with specific implement in expert badminton player," (in English), Neuroscience, Article vol. 275, pp. 10212, Sep 52014.

[28] A. Veraksa and A. Gorovaya, "Imagery training efficacy among novice soccer players," Procedia-Social and Behavioral Sciences, vol. 33, pp. 338-342, 2012.

[29] C. Battaglia et al., "Use of video observation and motor imagery on jumping performance in national rhythmic gymnastics athletes," (in English), Human Movement Science, Article vol. 38, pp. 225-234, Dec 2014.

[30] S. Bjorkstrand and P. Jern, "Evaluation of an imagery intervention to improve penalty taking ability in soccer: A study of two junior girls teams," (in English), Nordic Psychology, Article vol. 65, no. 4, pp. 290-305, 2013.

[31] A. Losana-Ferrer, S. Manzanas-Lopez, F. Cuenca-Martinez, A. Paris-Alemany, and R. La Touche, "Effects of motor imagery and action observation on hand grip strength, electromyographic activity and intramuscular oxygenation in the hand gripping gesture: A randomized controlled trial," Hum Mov Sci, vol. 58, pp. 119-131, Apr 2018.

[32] A. M. Mazli, T. K. A. Khan, and A. Hashim, "The effects of PETTLEP and traditional imagery interventions on netball players shooting accuracy," Jurnal Sains Sukan \& Pendidikan Jasmani, vol. 7, no. 2, pp. 53-60, 2018.
[33] F. R. Ramirez, "PETTLEP IMAGERY AND VIDEO-OBSERVATION: A MOTIVATION CASE STUDY OF FOUR BADMINTON PLAYERS," Polish Journal of Sport \& Tourism, vol. 17, no. 4, 2010.

[34] S. E. Williams and J. Cumming, "Measuring athlete imagery ability: the sport imagery ability questionnaire," $J$ Sport Exerc Psychol, vol. 33, no. 3, pp. 416-40, Jun 2011.

[35] S. Shalfawi, J. Ingebrigtsen, S. Rodahl, E. Enoksen, and E. Tonnessen, "Validity and reliability of the Brower timing system speed trap II," in 15th Annual ECSS Congress, Antalya, Turkey, 2010, pp. 2326.

[36] W. Bullock, D. Panchuk, J. Broatch, R. Christian, and N. K. Stepto, "An integrative test of agility, speed and skill in soccer: effects of exercise," J Sci Med Sport, vol. 15, no. 5, pp. 431-6, Sep 2012.

[37] A. Grillo, A. Rogers, and T. Perry, "Association of heart rate variability with perceptual-motor measures among ROTC cadets," 2020.

[38] P. G. Post and C. A. Wrisberg, "A phenomenological investigation of gymnasts' lived experience of imagery," The Sport Psychologist, vol. 26, no. 1, pp. 98-121, 2012.

[39] D. L. Garza and D. L. Feltz, "Effects of selected mental practice on performance, self-efficacy, and competition confidence of figure skaters," The Sport Psychologist, vol. 12, no. 1, pp. 1-15, 1998.

[40] P. Nekooei, T. Tengku-Fadilah, S. Amri, R. B. Baki, S. Majlesi, and P. Nekouei, "Anatomical Shoulder Movement Strength Imbalance Among Water Polo Overhead Athletes," vol. 7, no. 2, pp. 15-20, 2019.

[41] N. Pooya, M. Sara, S. Gholamreza, F. Tengku, and N. Paria, "Comparison of anthropometric parameters among Iranian 
and Spanish water polo players," vol. 5, no. 2, 2016.

[42] C. De Francesco and K. L. Burke, "Performance enhancement strategies used in a professional tennis tournament," International Journal of Sport Psychology, 1997.

[43] S. M. Kosslyn et al., "Bridging psychology and biology: the analysis of individuals in groups," American psychologist, vol. 57, no. 5, p. 341, 2002.

[44] S. Hammoudi-Nassib et al., "Time interval moderates the relationship between psyching-up and actual sprint performance," The Journal of Strength \& Conditioning Research, vol. 28, no. 11, pp. 3245-3254, 2014.

[45] M. A. Pain, C. Harwood, and R. Anderson, "Pre-competition imagery and music: The impact on flow and performance in competitive soccer," The Sport Psychologist, vol. 25, no. 2, pp. 212-232, 2011.

[46] K. J. Munroe-Chandler, C. R. Hall, G. J. Fishburne, and L. Strachan, "Where, when, and why young athletes use imagery: An examination of developmental differences," Research quarterly for exercise and sport, vol. 78, no. 2, pp. 103116, 2007.

[47] M. T. Iftikhar, C. J. Mallett, and M. A. Javed, "Imagery Improves Reaction Time in Elite Sprinters," 2018.

[48] C. Battaglia et al., "Use of video observation and motor imagery on jumping performance in national rhythmic gymnastics athletes," (in English), Hum Mov Sci, Article vol. 38, pp. 225-34, Dec 2014.

[49] Collet, F. Di Rienzo, N. El Hoyek, and A. Guillot, "Autonomic nervous system correlates in movement observation and motor imagery," (in English), Frontiers in
Human Neuroscience, Review vol. 7, p. 17, Jul 2013, Art. no. 415.

[50] J. Cumming, C. Hall, and C. Shambrook, "The influence of an imagery workshop on athletes' use of imagery," Athletic insight, vol. 6 , no. 1, pp. 52-73, 2004. 